\title{
BEHAVIOR OF SHIP OFFICERS IN MANEUVERING TO PREVENT A COLLISION
}

Bin Lin

Department of Merchant Marine, National Taiwan Ocean University, Keelung, Taiwan 20224, R.O.C., blin@mail.ntou.edu.tw

Follow this and additional works at: https://jmstt.ntou.edu.tw/journal

Part of the Business Commons

\section{Recommended Citation}

Lin, Bin (2006) "BEHAVIOR OF SHIP OFFICERS IN MANEUVERING TO PREVENT A COLLISION," Journal of Marine Science and Technology: Vol. 14: Iss. 4, Article 5.

DOI: 10.51400/2709-6998.2084

Available at: https://jmstt.ntou.edu.tw/journal/vol14/iss4/5

This Research Article is brought to you for free and open access by Journal of Marine Science and Technology. It has been accepted for inclusion in Journal of Marine Science and Technology by an authorized editor of Journal of Marine Science and Technology. 


\section{BEHAVIOR OF SHIP OFFICERS IN MANEUVERING TO PREVENT A COLLISION}

Acknowledgements

The author wants to specially thank Mr. YuenPing Chen for his assistance of carrying out the simulation experiments. 


\title{
BEHAVIOR OF SHIP OFFICERS IN MANEUVERING TO PREVENT A COLLISION
}

\author{
Bin Lin*
}

Key words: navigational safety, ship collision, simulation experiment.

\begin{abstract}
In recent years, increased ship size and traffic density have heightened the risk for collision. When a ship is exposed to such a risk, the officer in charge must take evasive actions appropriate with the circumstances to prevent this from happening. Such actions shall comply with the International Regulations for Preventing Collision at Sea. However, violations of the regulations can usually be found in collision cases. This study is focused on the actions of the officers in charge, and whether or not they obey the rules of the regulations, and what are the reasons for navigational faults. The assessment is performed by simulation experiment and questionnaire. The result reveals that the faults are mainly related to carelessness, personal attitude and lack of knowledge.
\end{abstract}

\section{INTRODUCTION}

In the maritime industry ship collisions have always been a concern to the public because of their resulting loss of human life, assets and/or damage to the environment. Although the International Maritime Organization (IMO) as well as the ship-owners has made significant efforts to improve navigational safety, collisions still happen without significantly decreased [11]. During the past twenty years there has been a considerable increase in the number of merchant ships, and the greatest increase has been in large ships. The result is that more ships and larger ships are congesting the coastal waters, requiring larger maneuvering room at sea. For many years the principle of the freedom to navigate has been recognized universally. The course and speed of a ship sailing at sea are decided by the ship's captain, with his knowledge and experience. Therefore the ship will continually meet other ships with different courses and situations during her voyage, and that often makes encounters between ships more complicated under high traffic density [6]. As a result, ships are inevitably exposed to the risk of a collision at sea.

Paper Submitted 10/17/05, Accepted 01/08/06. Author for Correspondence: Bin Lin.E-mail: blin@mail.ntou.edu.tw.

*Department of Merchant Marine, National Taiwan Ocean University, Keelung, Taiwan 20224, R.O.C.
Ship collisions can be seen as the result of cause and effect. When an officer faces an encounter, his decisions and actions will affect whether the encounter remains harmless, becomes better or worse, or develops into a collision. Before the officer acts, many factors must be considered, including the condition of the ship, the traffic situation, weather conditions, the sea room available, etc. Of course, whatever the action, it must comply with the International Regulations for Preventing Collisions at Sea, 1972. These regulations provide consistent maneuvering patterns for ships to follow [9]. One of the aims of the regulations is to bring greater safety to the conduct of collision avoidance maneuvers at sea.

To prevent some of the major causes of collision, proper manning of the ship, as well as proper education and training in how to avoid accidents at sea must be of prime consideration. Therefore, knowledge, experience and technical ability are essential elements for a qualified officer to maneuver a ship, and to prevent a collision. However, a competency certificate to an officer does not ensure that he will never make a navigational fault. In fact some ship officers have their own ideas as how to run a ship, and tend to disregard official regulations. They may take unpredictable actions violating the rules for avoiding collision, and this contravention is a main factor contributing to collisions [3]. In most collision cases one or sometimes both of the ships involved are found to have contravened the regulations. Disobedience of the regulations is usually assumed to be a human failure.

Most papers regarding navigational safety mainly analyze the results of the actions officers took in collision cases, but they rarely discuss the causes of these faults $[2,3,8]$. This paper is focused on the analysis of navigational errors in the taking of actions to avoid collision. The remainder of this paper is laid out as follows. When officers encounter another vessel, they must take steps in compliance with collision regulations as described in Section 2. Questionnaire and simulation experiment used for collecting data are developed in Section 3. Results of the questionnaire and experiment are shown in Section 4. The data are analyzed in Section 5 to determine the concerns of the participants and the 
causes of the navigational errors. And finally, the practical implications of the main results derived from the analysis are addressed in Section 6.

\section{ACTIONS TO AVOID COLLISION}

When a ship is under power on a busy waterway, then obviously many other ships are doing the same thing in the same area at the same time. These ships can usually be seen or detected within a 10 mile radius by either the ship's officer by plain sight or by radar. In practice an officer must diligently watch the development of any situation between his/her own ship and any other vessel, and carefully take collision avoidance action if there is any risk at all. The process of the action is described as follows.

First, the officer needs to check whether there is any approach that is threatening to the ship. The threat includes any ship encounter that may result in a collision risk. There is a safety-zone around the ship which an officer likes to keep clear of other vessels. A ship encounter is defined as any situation where a ship approaches near or within that safety-zone around the ship [7]. Collision risk can be said to occur when there is an encounter where the closest point of approach (CPA) between two ships will reach near zero if no action is taken. In other words, if the compass bearing of an approaching ship does not change appreciably, the two ships will collide. Therefore every officer carefully maintains a proper look-out to observe other ships' movements so as to make a full appraisal of the risk.

If the risk is inevitable, the officer must then consider how close the CPA will be allowed to become before taking action. This depends on the circumstances at the time, including navigable sea room, ship specifications, traffic density, weather conditions, visibility, etc. On the high seas it is dangerous to approach another ship close enough to risk collision because any fault from either of the ships may result in a collision under that circumstance [1]. The CPA must always be a safe distance for passing another vessel so as to avoid collision.

The third step is to consider which method is the best to overcome the risk. It is now essential for the officer that $\mathrm{s} / \mathrm{he}$ is fully conversant with the official collision regulations. When faced with a head-on situation so as to involve risk of collision in compliance with the rule of the sea: each vessel shall alter her course to starboard so that each shall pass on the port side of the other [9]. The action of altering course to port for collision avoidance is definitely forbidden because that may incur the danger of collision if the other ship complies with the rules to turn to starboard at the same time.
In a crossing situation involving risk of collision, the vessel which has the other on her starboard side shall comply with the rule: she shall keep out of the way and shall, if the circumstances of the case admit, avoid crossing ahead of the other vessel [9]. Therefore according to the rule the vessel shall take action to alter course to starboard or reduce speed. The altering of course to port side is not forbidden, but it is not recommended, because the rule requires that the ship shall avoid crossing ahead of the other ship. The giveway ship can easily resolve the crossing situation by simply altering its course to starboard if there is sufficient sea room, and this will be more effective than a change of speed to avoid the right-of-way ship. In restricted visibility any ship shall avoid altering its course to port for the prevention of a collision [9].

Fourth, the officer in charge must decide when to take action, so as to increase the final CPA. According to the regulations any action shall be taken in ample time. Every ship which by the rules must keep out of the way of another ship shall take early and substantial action to keep well clear. The earlier the action is taken, the larger the final CPA. In the case a ship is in a headon situation, and when the collision point is at 2 miles, then by changing its course 10 degrees, the ship's position will have left the original course line by 0.34 miles when arriving at the theoretical point of impact; in case the same action is taken when 4 miles apart, then the final CPA increases to 0.68 miles by one ship's maneuver alone. Regulations do not provide a definite range of taking action to avoid collision, but for a crossing situation involving two ships under power on the open sea it is suggested that action be taken at a distance of 5 to 8 miles between two ships [4].

At the same time the ship's officer also needs to determine by how many degrees the ship needs to change course, or by how many knots the ship needs to reduce speed. In the above case, when the ship changes course by 20 degrees when 2 miles apart, the final CPA also can be reached to 0.68 miles. A large change will get a large CPA the same as an early action. The alteration of course must be sufficiently large so as to be readily apparent to the other ship observing visually or by radar.

After the officer has taken action, s/he must determine its effectiveness, and shall carefully check and remain vigilant until the other ship has passed, and both ships are clear of one another. If it is determined that the action taken will not achieve the desired CPA, then additional evasive actions must be taken.

A ship on collision course with another ship must have been observed by sight or radar for some time. Any collision that may have developed from an encounter rarely happened without enough time for prevention. The above steps of preventing a collision are basic 
knowledge for any competent officer. However, an officer is sometimes unable to follow the rules, especially under reduced visual condition. Almost without exception, the individual violations of the regulations by one or both ships are contributing factors in a collision. The following case is an example.

On June 221995 two cape-size bulk carriers, Mineral Dampier and Hanjin Madras collided in the East China Sea under reduced visibility. As a result of the collision, the Mineral Dampier sank quickly and all 27 of her crew were lost [10]. Hanjin Madras, the giveway ship in the crossing situation, did not slow down or turn to starboard until the last moment; she bore the greater blame, 80 per cent. Mineral Dampier was to maintain her course and speed, and altered course to port just prior to the collision; this wrong action let her bear 20 per cent of the blame for the collision.

Although collision regulations have been ratified for 30 years, violation of these regulations is nearly always a main contributing factor in ship collisions. The above case which show misinterpretation of the rules and no appreciable action being taken to avoid collision until it was too late, are only one of hundreds of ship collisions due to often blatant violations of collision regulations. These kinds of casualties are normally attributed to navigational errors. Consequently improving officers' training so as to enable them to reduce collisions becomes a common objective in the maritime industry. However, most officers involved in collisions had completed a full training course and had passed adequate examinations, and were familiar with the regulations before obtaining their competency certificates. So why did their behavior contravene the regulations, resulting in a collision? There must be an underlying reason why so many make these errors. Besides, in addition to these incidents because of noncompliance with the regulations that resulted in a collision, obviously many more resulted in near misses. Therefore an analysis of the maneuvers carried out, and the thought processes and considerations by the officers in charge of the ships involved may be helpful to increase the effectiveness of future training. In this study the above objectives are achieved by questionnaire and simulation experiment.

\section{RESEARCH METHODS}

This study focused on the ship's maneuvers in order to examine the behavior of the ship's officers avoiding a collision. Simulation is a powerful analysis tool for studying system dynamics and realizing system problems where it would be impossible or impractical to study the real situation [5]. Experimentation using a simulated traffic flow provides us with the ability to examine navigational problems. For obtaining a comprehensive understanding of the expectations of the officers when facing the risk of a collision, it was decided to complement the study by means of a questionnaire in which the input of the subjects was elicited. Before starting the simulation experiment, each subject had to answer some questions. The answers revealed their understanding of collision regulations and were compared with their actions in the exercises.

The simulation experiment in this study was designed to assess the mariners' actions in avoiding dangerous encounters, and to test the effectiveness of the current regulations for preventing collisions at sea in certain pre-determined situations. To achieve the purpose of the study, different encounter situations and operation scenarios were repeated many times for building up a statistically significant sample of responses. The experiment was carried out using the ship handling simulator at the National Taiwan Ocean University. The simulator, a real time simulator, has a full-size bridge compartment. The visual system of the simulator generated a colored picture of the environment with appropriate display of visibility scenes. This was considered to be the closest approach to the real life situation while at the same time retaining full control over the experimental conditions.

The potential encounter in the experiments involves two ships, the own ship controlled by each subject and another target ship. The own ship in this study was a large container ship with a displacement of 40000 tonnes. The target ship was also a container ship. There were two situations for the simulation experiment comprising a head-on situation and a crossing situation. Both situations were to be carried out in day time under both good and poor visibility, respectively. In all the experimental scenarios, the own ship maneuvered with $000^{\circ}(\mathrm{T})$ initial course and 20-knot initial speed within an open sea. The initial position of the target ship in the head-on scenario was 10 miles ahead of the own ship on a course at $180^{\circ}$, and in the crossing scenario it was bearing $022.5^{\circ}$ and 9.25 miles away from the own ship starboard bow on a course of $225^{\circ}$. Therefore in the crossing situation the own ship was the give-way ship. The target ship kept moving at her course and speed in all scenarios.

\section{RESULTS OF QUESTIONNAIRE AND EXPERIMENTS}

The experiments were performed using 40 qualified ship officers, including 10 master mariners, 7 chief mates and 23 senior mates. The actions of each subject was recorded and indicated how each subjects acted to avoid the particular encounter situation. Total 40 ship tracks in each exercise are shown in Figures 1 and 2. 


\section{Head-on situation}

In the questionnaire, the first questions asked if a vessel meets a head-on situation at sea, what kind of actions should be taken. All subjects indicated to alter their course to starboard in accordance with the rule, but 4 of the subjects also indicated that they would only do so if necessary. When being asked regarding the timing of taking action to avoid collision in this situation, 19 subjects agreed to order the action at a distance between ships of over 5 miles. Among the remaining subjects there were 3 that thought the distance should be only 3 miles. If the situation of the question was changed to poor visibility, the number of subjects agreeing to a distance of over 5 miles increased to 26 . The last question asked about the safe distance to the other ship after their actions. 19 subjects expected a CPA of over one mile under good visibility, and that number increased to 24 when the visibility was poor.

In the simulation exercise under good visibility, when the subjects faced the head-on collision situation, 37 subjects altered course to starboard, and the remaining 3 subjects altered their course to port for the avoidance in contravention of the regulations. Twenty-two subjects ordered the action to be taken at a distance between ships of over 5 miles, and the rest were too late

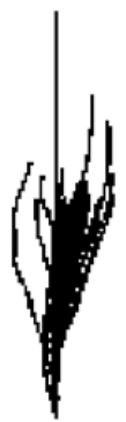

(a) Good visibility

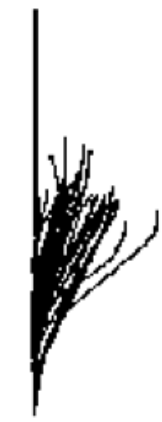

(b) Poor visibility
Fig. 1. All ship tracks in head-on situation.

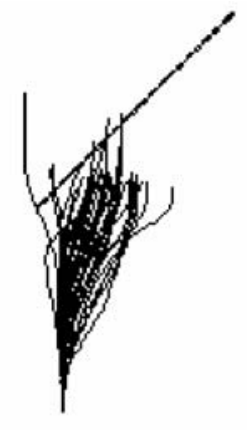

(a) Good visibility

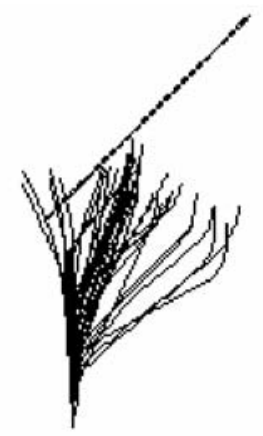

(b) Poor visibility
Fig. 2. All ship tracks in crossing situation. in taking their avoiding action. No subject got a CPA of over one mile, and the smallest CPA was only 0.07 mile. The mean CPA was 0.407 miles. In the same exercise, but under poor visibility, all subjects altered their course to starboard, and 26 subjects took the action over 5 miles. Consequently the results showed a CPA of over one mile in 13 tracks. The mean CPA increased to 0.789 miles. Figure 3 shows the distance and Figure 4 shows the CPAs in the head-on situation under good and poor visibility, respectively.

\section{Crossing situation}

In the questionnaire, when asked about a crossing situation with the other ship on starboard side, all subjects agreed to keep out of the way by altering their courses to starboard for taking collision avoidance action in accordance with the rules, but one of the subjects also agreed to alter course to port if it was necessary, and he had the same answer in the head-on situation. Twenty-four subjects agreed to order the action at the distance over 5 miles, and the number of subjects increased to 29 under poor visibility. Seventeen subjects expected a CPA of over one mile under good visibility, and 25 subjects expected that under poor visibility.

In the simulation exercise under good visibility, facing the risk of collision, 36 subjects altered their course to starboard, but the remaining altered their course to port for avoiding collision, and one of them finally changed it back to starboard. There were 18

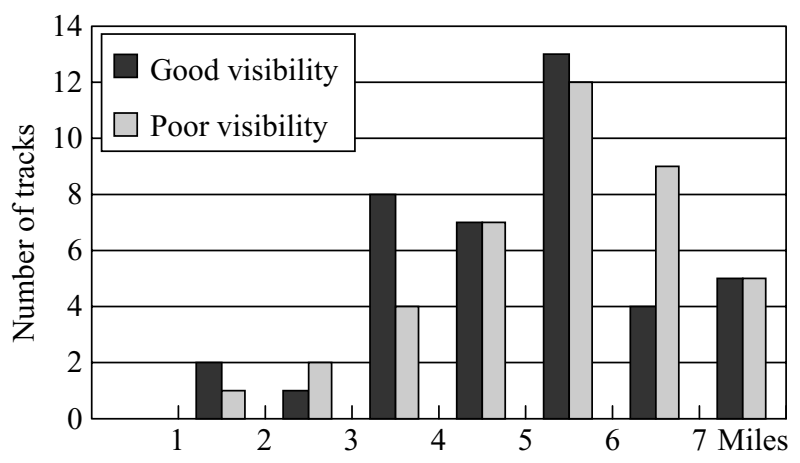

Fig. 3. Distance between ships in head-on situation.

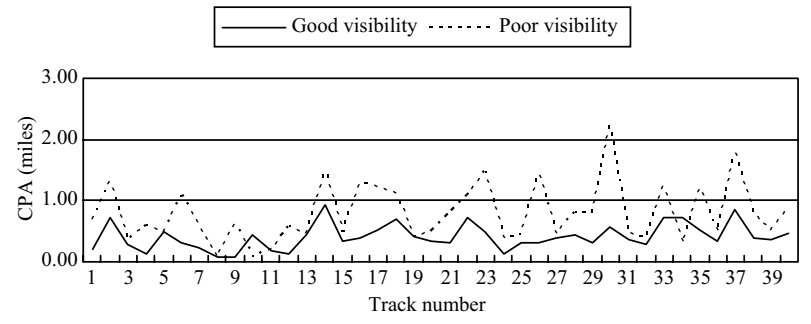

Fig. 4. CPA of each track in head-on situation. 
subjects that took their action at a distance of more than 5 miles. Only 8 subjects kept the CPA to more than one mile. The mean CPA was 0.685 miles. Under poor visibility, 35 subjects altered their course to starboard, and 23 subjects took the action over 5 miles, as shown in Figure 5. The results showed 14 CPA tracks of over one mile, as shown in Figure 6. The mean CPA increased to 1.305 miles. There were 2 subjects who altered course to port in both exercises of this experiment.

\section{MANEUVERING BEHAVIORS IN NAVIGATIONAL FAULTS}

The results of the questionnaire reveal understandings of the subjects on collision regulations, and those of the experiment reveal their practical behaviors when facing the risk of a collision. We found that many ship officers realized that the course alteration to starboard in both situations was the action required by law. But in practice, their behaviors were even worse than their understanding. Some of the officers disregarded the rule altogether and altered course to port. After the simulation exercises, the subjects were asked for the reason for their action, and the answer was that the action was an easier maneuver than to alter to starboard. Fortunately the target ship had a fixed course and speed and so there was no response from the target ship to add to the risk, or in a head-on situation, if the target had altered the course to starboard, a collision might have been difficult to avoid.

Although the time the subjects required to take

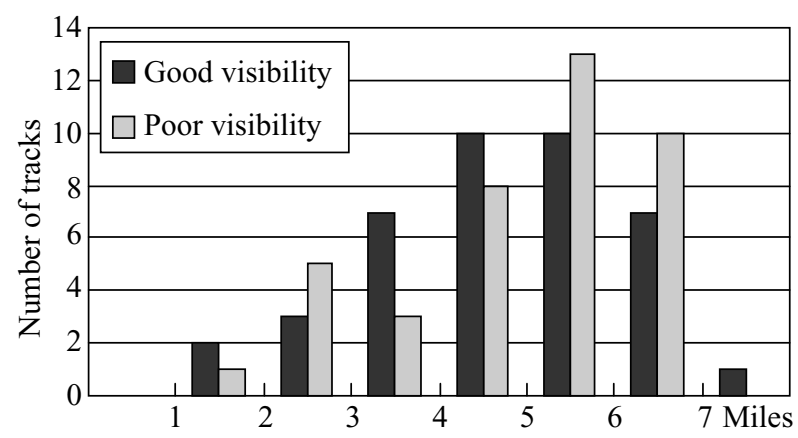

Fig. 5. Distance between ships in crossing situation.

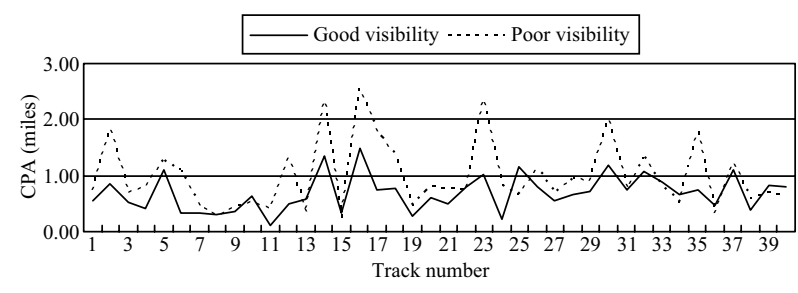

Fig. 6. CPA of each track in crossing situation. their action in the simulation exercises was not much difference from their responses in the questionnaire, the mean CPA in the simulation exercises was smaller. Comparing the CPAs in the experiment with those in the questionnaire by statistics test resulted in a significant difference. Some subjects took their actions too late and some subjects made their course change too small in order to control the CPA to be more than one mile in the exercises. Even when the risk of the encounter escalating to a collision became obvious, some subjects still kept on their courses until the last moment, or changed course less than 5 degrees. The results of the above actions almost always resulted in small CPAs. Through oral questioning, the reason was that the subjects were very confident and did not think a large CPA was required in exercises.

Basically the collision regulations only provide a principle guideline of removing the risk of collision. Except altering course to starboard in a head-on situation and in a crossing situation under restricted visibility being regulated, other elements in the action including the time of performance, change range and final CPA, even the direction of altering course in a crossing situation under good visibility, are not regulated. In response to a situation where there is a risk of collision, a ship's officer may take avoiding action by altering ship course and/or ship speed, and s/he may make an early or a late decision, and s/he may change a large or small course with a long or short period to get a large or small CPA. At the same time this action may take the form of a single maneuver or a sequence of maneuvers. These are only regulated in principle, not prescribed and quantified.

The requirement of each action to avoid collision with another ship is to pass at a safe distance. To achieve this purpose any altering of course must be large enough and made in ample time. But in our experiment, an officer realized that to give way did not mean that his action would get a safe CPA. No collisions happened, but about $17.5 \%$ of the total tracks in the good visibility exercise had a CPA of less than 0.2 miles, and could be classified as near misses. The results could not be called "safe" under any circumstance, as any minor error by either or both ships would have resulted in a catastrophic accident..

Our experiment in this study makes a few points. The first is that a ship's officer who lacks sufficient knowledge regarding collision regulations is more inclined to alter course to port. Two of the four subjects who agreed to alter course to port in the questionnaire actually took the same action in the simulation experiment.

The second point is that violation of the collision regulations is a behavior of sudden impulse for a few 
officers, not lack of knowledge. Except for the above 2 subjects, the remaining subjects that took action to the port-side knew about the requirements in the regulations. Ship tracks show that a few officers sometimes disregard situations and take unpredictable action and alter their course to port-side.

Third, how ship officers make their decision to avoid collision is related to their personal characteristic. When there is sufficient sea room, there is no obstacle on their route, and it is very easy to get a large CPA for safety through early action and/or a large change of course. Five subjects took avoiding action resulting in a CPA of less than one mile in all the exercises. When there is a risk of collision any ship that desires to stay out of the way of an approaching vessel had better, as far as possible, take early action to keep well clear. The later avoidance action is taken, the less effective it will be, and the closer the CPA. As a result, if there is any failure by human or machinery, the possibility of a collision increases dramatically.

Fourth, ship officers take collision avoidance actions with more caution under poor visibility. When the movement of the other ship can be clearly observed, they seem to take the risks involved less seriously. This may be due to the fact that they have to pay close attention when judging the circumstances by means of a radar display. The CPAs under different visibility situations were investigated in this experiment, and a significant difference could be found. In the whole process of avoiding collision, the results of the actions to avoid collision under poor visibility were apparently safer than in good visibility in both situations.

\section{CONCLUSIONS}

In this study we found that many ship officers carefully comply with the regulations to take action by alternating their course to starboard in head-on or crossing situation. But some ship officers did not realize the regulations very well resulting in improper, and in some cases illegal behaviors. Sometimes their behavior was illegal due to lack of discipline and care. Some officers disobeyed regulations simply because in certain situations they considered the expediency of their action and disregarded the maneuvering behavior of the other mariners.

For these officers, it is likely that strict training may be required to make them realize the requirements of the regulations and the need to follow the rules. It is crucial that any training emphasizes navigational safety. A larger CPA can be obtained through earlier action and a larger change in course, and can greatly reduce the risk of collision. Such training can use a simulator to increase the trainees' experience in collision avoidance.
Maritime industries have generally accepted that the efficiency of training by means of simulators is superior to all other known methods, because simulation training provides advantages over other techniques in areas of safety and repeatability.

Shipping companies have the responsibility to employ competent and conscientious officers, and ship masters have the responsible to train and supervise the actions of their officers when making collision avoidance maneuvers. The lack of maneuvering behavior of some officers could possibly be evaluated by masters and companies, and these offices must be dismissed. Marine safety depends on the fact that all officers are fully conversant with and comply with the marine regulations at all times.

\section{ACKNOWLEDGEMENTS}

The author wants to specially thank Mr. YuenPing Chen for his assistance of carrying out the simulation experiments.

\section{REFERENCES}

1. Abdelgalil, E.M., "Shipping Casualties and Ship's Domain," Proceedings of the Third International Symposium on Marine Traffic Service, UK, pp. 95-101 (1978).

2. Cockcroft, A.N., "The Circumstances of Sea Collision," Journal of Navigation, Vol. 35, pp. 100-112 (1982).

3. Cockcroft, A.N., "Cause Relationships of Collisions and Groundings," Journal of Navigation, Vol. 35, pp. 305311 (1982).

4. Cockcroft, A.N. and Lameijer, J.N.F., A Guide to the Collision Avoidance Rules, Butterworth Heinemann Ltd., UK, pp. 115-116 (2001).

5. Curtis, R.G., 'The Probability of Close Overtaking in Fog," Journal of Navigation, Vol. 33, pp. 100-112 (1980).

6. Goodwin, E.M., "A Statistical Study of Ship Domains," Journal of Navigation, Vol. 28, pp. 328-344 (1975).

7. Goodwin, E.M., "Marine Encounter Rates," Journal of Navigation, Vol. 31, pp. 357-369 (1978).

8. Hukushima, H., "Factors Contributing to Marine Casualties," Journal of Navigation, Vol. 29, pp. 135-140 (1976).

9. IMO, International Regulations for Preventing Collisions at Sea, 1972, International Maritime Organization, London, UK (1972).

10. Lloyd's of London Press, "The Mineral Dampier and Hanjin Madras," Lloyd's Law Report, Vol. 1, pp. 282-291 (2000).

11. Manen, S.E. and Frandsen, A.G., "Ship Collision with Bridges, Review of Accidents," Proceedings of the International Symposium on Advances in Ship Collision Analysis, Denmark, pp. 3-11 (1998). 